\title{
Índices de calidad del agua en la microcuenca de la quebrada Victoria, Guanacaste, Costa Rica (2007-2008)
}

\author{
Bi Yun Zhen-Wu \\ Laboratorio de Geoquímica, Instituto Costarricense de Electricidad (ICE), Guanacaste, Costa Rica; biyun29@gmail.com
}

Recibido 4-XII-2009 Corregido 6-I-2010 Aceptado 9-II-2010

\begin{abstract}
Indices of water quality in the watershed of Victoria creek, Guanacaste, Costa Rica (2007-2008). Costa Rican Guidelines for the Evaluation and Classification of the Surface Waters (IHCA-CR) and the National Sanitation Foundation of the USA (U.S.NSF) water quality indexes, were evaluated during the hydrology year 2007-2008 in Victoria Creek, Costa Rica. A total of 15 sampling sites composed the monitoring network. The water had an incipient contamination (range 4-6 points, IHCA-CR index) and good quality (range 71-90 points, U.S.NSF index) and was moderately hard (range $68-82 \mathrm{mgL}^{-1} \mathrm{CaCO}_{3}$ ) in $87 \%$ de sampling sites and soft (range $33-52 \mathrm{mgL}^{-1} \mathrm{CaCO}_{3}$ ) in $13 \%$ of sampling sites. The dominant type of water in the 2008 dry season was calcium-magnesium sulfate ( $47 \%$ of sampling sites), followed by the calcium sulfate ( $27 \%$ of sampling sites); the remaining sites (26\%) had a mixture of hydrogencarbonate and sulfate water. Future monitoring of the water quality and geothermal development effects in the basin should incorporate the following indicators: fecal coliform as bacterial contamination; turbidity as physical quality; dissolved oxygen percentage as aquatic system state; conductivity as dissolved ions content; water temperature as thermal contamination; and chloride as geothermal water tracer.
\end{abstract}

\section{KEY WORDS}

Physicochemical water quality, bacteriological water quality, water quality index, geothermal development effect, Victoria River.

\section{RESUMEN}

Se evaluó, durante el año hidrológico 2007-2008, la calidad del agua de la quebrada Victoria, Costa Rica, mediante la aplicación de los índices de calidad del agua del Reglamento costarricense para la evaluación y clasificación de la calidad de cuerpos de agua superficiales (IHCA-CR) y el de la Fundación Nacional de Sanidad de los Estados Unidos (ICA-U.S.NSF), para establecer una línea base para los programas de seguimiento de su calidad y de los efectos del desarrollo geotérmico. La red de muestreo comprendió 15 sitios. Se encontró en el agua de la quebrada una contaminación incipiente (entre 4 y 6 puntos), según el IHCA-CR, y un calidad buena (entre 71 y 90 puntos), según el ICA-U.S.NSF. El agua según su dureza total como carbonato de calcio se clasificó en moderadamente dura (entre $68 \mathrm{mgL}^{-1}$ y $82 \mathrm{mgL}^{-1}$ de $\mathrm{CaCO}_{3}$ ) en $87 \%$ de los sitios y blanda (entre $33 \mathrm{mgL}^{-1}$ y $52 \mathrm{mgL}^{-1}$ de $\mathrm{CaCO}^{3}$ ) en $13 \%$ de los sitios. El tipo de agua según la caracterización geoquímica que predominó en la época seca del 2008, fue la sulfatada cálcica-magnésica (47\% de los sitios), seguida de la sulfatada cálcica ( $27 \%$ de los sitios) y los sitios remanentes $(26 \%$ ) en mezclas de aguas hidrogenocarbonatas y sulfatadas. Para los programas de seguimiento de la calidad del agua de la quebrada y de efectos del desarrollo geotérmico en la microcuenca, debe incluir los siguientes indicadores: de contaminación fecal, los coliformes fecales; de calidad física, la turbiedad; del estado de los sistemas acuáticos, el porcentaje de saturación de oxígeno disuelto; del contenido de sales disueltos, la conductividad; de contaminación térmica, la temperatura del agua; de trazador de aguas geotérmicas, el cloruro.

\section{PALABRAS CLAVE}

Calidad físico-química del agua, calidad bacteriológica del agua, índice de calidad del agua, efectos desarrollo geotérmico, quebrada Victoria.
Las aguas superficiales, como las de las nacientes y los ríos, y subterráneas son vulnerables a diversas fuentes de contaminación por sustancias químicas o microorganismos patógenos, ya sea de origen natural o por intervención humana (WWPA 2003). La calidad natural del agua está determinada por las condiciones geomorfológicas del suelo y es relevante para evaluar si una variación en la concentración de los parámetros medidos se debe a cambios naturales o a efectos de las actividades humanas, incluyendo el desarrollo geotérmico (Bianchini et al. 2005). 
De ahí la importancia del establecimiento de una línea base para analizar las tendencias a lo largo del tiempo.

La evaluación de la calidad del agua es el proceso de valoración de la naturaleza física, química y biológica del agua en relación con la calidad natural, los efectos humanos y los usos deseados, principalmente, los que puedan afectar la salud humana y la de los sistemas acuáticos (Chapman 1996). Se define en función de un conjunto de parámetros físico-químicos y/o microbiológicos, así como de sus valores de aceptación o de rechazo, y son útiles para evaluar puntualmente los contaminantes específicos presentes en el agua (Arcos et al. 2005). Los índices son herramientas rápidas para conocer en forma general el estado de un cuerpo de agua y observar su tendencia evolutiva (Sancha \& Espinoza 2001).

Los trabajos de mayor importancia a nivel mundial se deben al índice desarrollado por la Fundación Nacional de Sanidad de los Estados Unidos (U.S.NSF, por sus siglas en inglés), por ser el más utilizado y modificado en muchos países del mundo, tales como España, Brasil y Colombia, entre otros (Samboni et al. 2007). En Costa Rica se aprobó en 2007 el Reglamento para la evaluación y clasificación de la calidad de cuerpos de agua superficiales, que incorpora el uso de índice para evaluar su calidad físicoquímica (Costa Rica 2007).
En la actualidad los índices desarrollados involucran desde un parámetro hasta más de 30 y no existe uno universal debido a las condiciones y los problemas ambientales específicos de cada área (Samboni et al. 2007). Por esto, la aplicación y el seguimiento continuo de cada parámetro permiten adecuar el índice a nivel regional y local.

La microcuenca de la quebrada Victoria (Fig. 1) abarca un área de $4,14 \mathrm{~km}^{2}$ y se localiza en la parte noroeste de Costa Rica. Sus aguas drenan a la subcuenca del río Colorado, el cual desagua en la cuenca del río Tempisque y desemboca en el océano Pacífico.

La quebrada Victoria se ubica en el sector suroeste del complejo volcánico Rincón de la Vieja-Santa María. Al noreste se encuentra la zona con las manifestaciones geotérmicas superficiales más grande del país, Las Pailas, cuyo campo geotérmico está siendo desarrollado por el Instituto Costarricense de Electricidad (ICE 2005). Estos fluidos se caracterizan por alta temperatura $\left(\right.$ de $20^{\circ} \mathrm{C}$ a $96^{\circ} \mathrm{C}$ ) y salinidad (de $50 \mathrm{mgL}^{-1}$ a $60 \mathrm{mgL}^{-1}$ de boro, de $2 \mathrm{mgL}^{-1}$ a $3 \mathrm{mgL}^{-1}$ de fluoruro y de 6000 a $7000 \mathrm{mgL}^{-1}$ de cloruro) (Tassi et al. 2005), por lo que constituyen un riesgo potencial de contaminación con estas sustancias para la quebrada.

La captación del acueducto de Curubandé, distrito del cantón de Liberia, de la provincia de Guanacaste de Costa

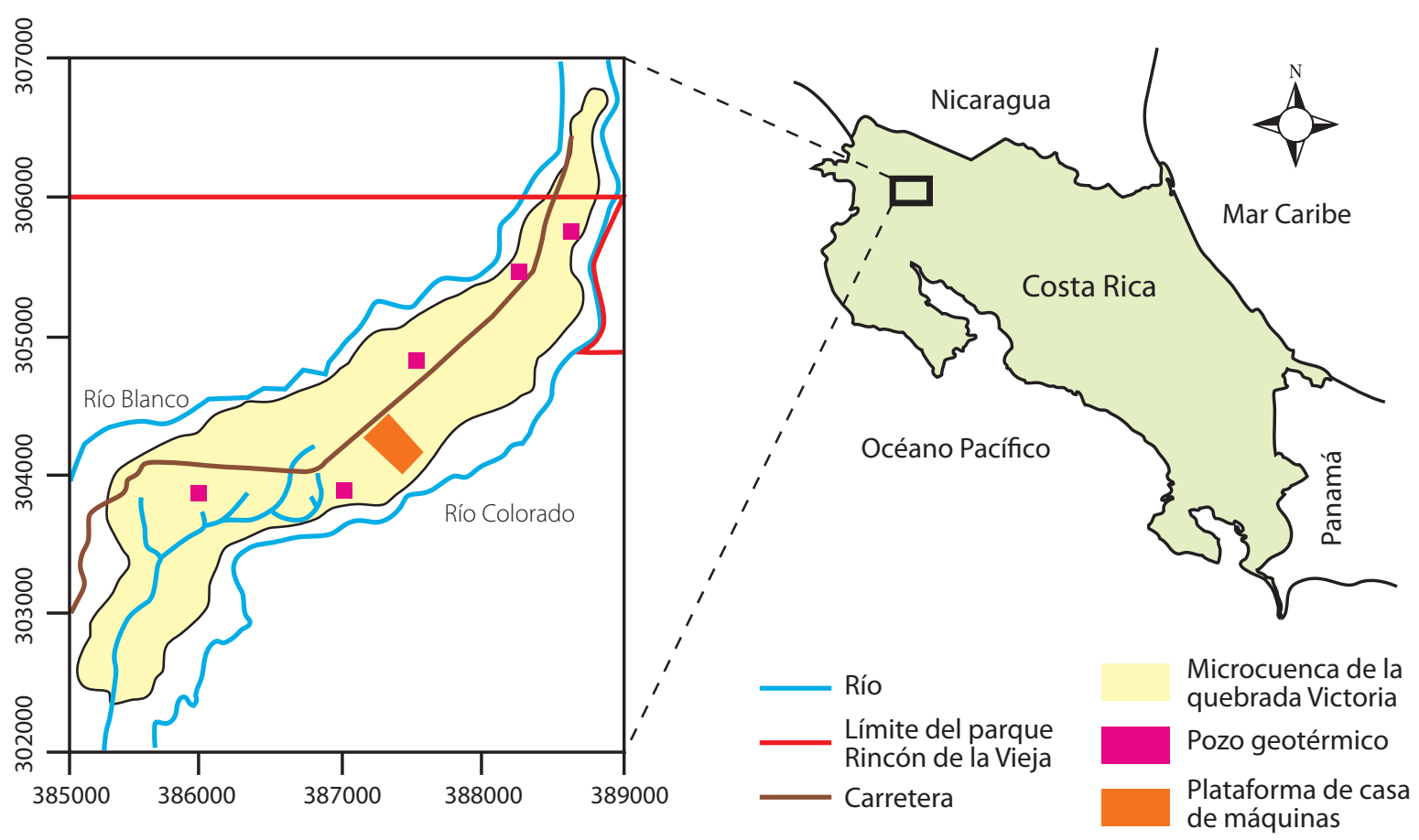

FIG. 1. Microcuenca de la quebrada Victoria, 2007-2008, Costa Rica. 
Rica, que abastecía en el 2002 a una población de 1812 personas (INEC 2002), se ubica en la parte baja de la microcuenca de la quebrada Victoria. Por esto, la caracterización geoquímica de estas aguas permite determinar la futura degradación de su calidad por las actividades humanas que se desarrollan en su parte media y alta (Bianchini et al. 2005). Aunado a esto, el uso de índices de calidad del agua es una herramienta comunicativa y entendible para los diferentes actores involucrados en el manejo y la gestión del recurso hídrico.

El objetivo de esta investigación fue evaluar la calidad del agua de la quebrada Victoria, mediante la aplicación de índices y caracterización química, para establecer una línea base para los programas de seguimiento de los efectos del desarrollo geotérmico en la microcuenca.

\section{METODOLOGÍA}

\section{Sitios de muestreo}

Se evaluaron 15 sitios de muestreo (Fig. 2, nacientes: sitios 5, 7, 9, 13, 14 y 15; toma del acueducto de Curubandé: sitio 1; lugares a lo largo de la quebrada: sitios 2, 3, 4, 6, $8,10,11$ y 12) comprendidos entre la naciente de la quebrada Victoria y la toma del acueducto de Curubandé. La selección de los sitios se basó en la identificación de las

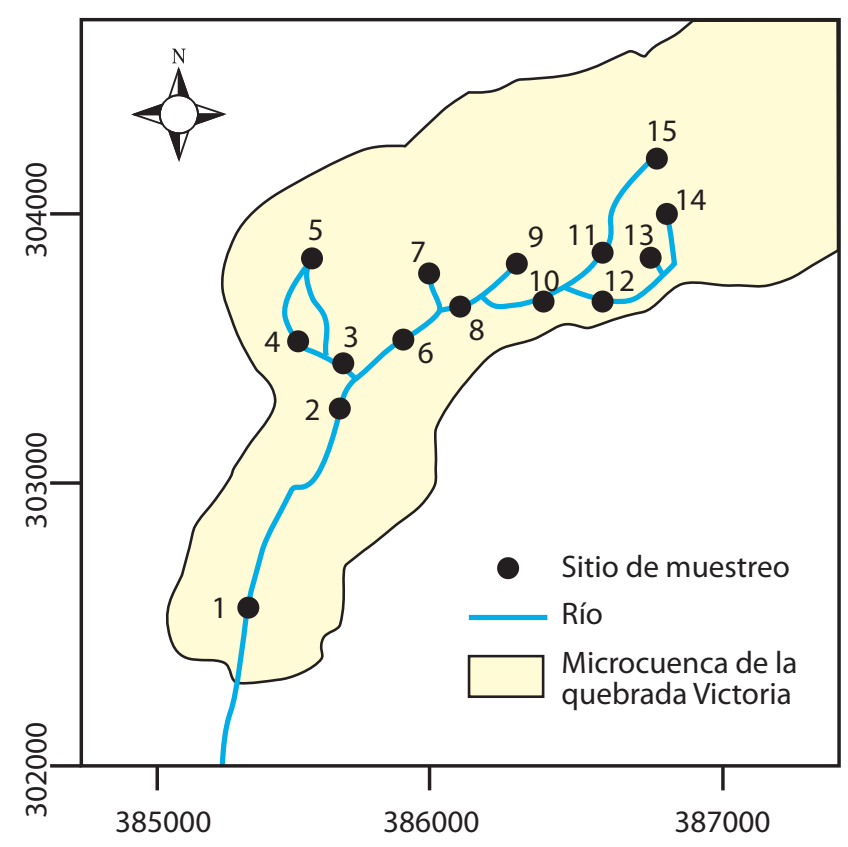

FIG. 2. Sitios de muestreo de la quebrada Victoria. nacientes y los puntos a lo largo del cauce durante los recorridos efectuados en la época lluviosa de 2006 y seca de 2007. Se realizaron en total cinco muestreos: dos en la época lluviosa (11 de setiembre y 6 de noviembre de 2007), dos en la seca (29 de enero y 26 de febrero de 2008) y una en la transición seca a lluviosa (3 de junio de 2008).

Se recolectaron muestras simples comenzando por la parte baja de la microcuenca (del sitio 1 al 15), entre las 9:00 y 16:00 horas, siguiendo los protocolos de los métodos normalizados para aguas potables y residuales (Eaton et al. 2005). Se midieron in situ: la temperatura del ambiente ( $\mathrm{T} \mathrm{amb}$ ) con un termómetro de mercurio; el potencial del hidrógeno $(\mathrm{pH})$, la temperatura $\left(\mathrm{T}_{2} \mathrm{O}\right)$ y la conductividad eléctrica (CE) del agua con un medidor de multivariables portátil (WTW 330i, Alemana). Se midió el caudal con un molinete (Seba D-87600 Kaufbeuren, F12169, modelo Z6, Alemana) entre las 48 y 72 horas después del muestreo.

\section{Muestreo y análisis de indicadores de calidad del agua}

En cada muestreo se recolectaron por sitio de muestreo las siguientes muestras: dos de un litro, conservadas entre $4^{\circ} \mathrm{C}$ y $10^{\circ} \mathrm{C}$, para el análisis de los parámetros: demanda bioquímica de oxígeno de cinco días $\left(\mathrm{DBO}_{5}\right)$ con el método de Winkler; sólidos disueltos (TDS) por gravimetría; boro (B) por espectrofotometría de ultravioleta-visible con curcumina; fluoruro $(\mathrm{F})$ con electrodo selectivo de iones; nitrato $\left(\mathrm{NO}_{3}{ }^{-}-\mathrm{N}\right)$, fosfato $\left(\mathrm{PO}_{4}{ }^{3-}-\mathrm{P}\right)$, sulfato $\left(\mathrm{SO}_{4}{ }^{2-}\right)$ y cloruro $\left(\mathrm{Cl}^{-}\right)$por cromatografía líquida de alta resolución. Además, una de $300 \mathrm{~mL}$ para el porcentaje de saturación de oxígeno disuelto (PSO) por el método Winkler; una de $125 \mathrm{~mL}$, tapadas sin burbujas de aire, para el análisis de hidrogenocarbonato $\left(\mathrm{HCO}^{3-}\right)$ por titulación ácido-base; una de $100 \mathrm{~mL}$, tratadas con ácido nítrico $50 \% \mathrm{vv}-1$, para la determinación de sodio $\left(\mathrm{Na}^{+}\right)$, calcio $\left(\mathrm{Ca}^{2+}\right)$ y magnesio $\left(\mathrm{Mg}^{2+}\right)$ por absorción atómica con llama; una de $100 \mathrm{~mL}$, tratadas con ácido clorhídrico $50 \%$ vv-1, para el análisis de nitrógeno amoniacal $\left(\mathrm{NH}_{4}{ }^{+}-\mathrm{N}\right)$ con electrodo selectivo de iones; y una de $500 \mathrm{~mL}$ como control. Estos análisis fueron realizados en el Laboratorio de Geoquímica del ICE (Guayabo de Bagaces, Guanacaste) según los métodos normalizados para aguas potables y residuales (Eaton et al. 2005) y del Organismo Internacional de Energía Atómica (IAEA 2003). Adicionalmente, se recolectaron una de $200 \mathrm{~mL}$ para el análisis de turbiedad (Turb) y una de $100 \mathrm{~mL}$ en bolsa Whirl-pak, conservada entre $4^{\circ} \mathrm{C}$ y $10^{\circ} \mathrm{C}$, y transportada dentro de las 24 horas al Laboratorio Nacional de Aguas del Instituto Costarricense de Acueductos y Alcantarillados (AyA) en Puntarenas para la determinación de coliformes fecales (CF). 


\section{Criterios para evaluar la calidad del agua}

La calidad del agua de la quebrada Victoria se evalúo a lo largo de su cauce mediante los índices: holandés de calidad del agua (IHCA-CR) (Cuadro 1, Costa Rica 2007) y el de la Fundación Nacional de Sanidad de los Estados Unidos (ICA-U.S.NSF) (Cuadro 2, NSF 2007) y se mapeó utilizando un sistema de información geográfica (SIG). El primero incorpora los parámetros: $\mathrm{PSO}, \mathrm{DBO}_{5}$ y $\mathrm{NH}_{4}{ }^{+} \mathrm{N}$; mientras que, el segundo: $\mathrm{PSO}, \mathrm{CF}, \mathrm{pH}, \mathrm{DBO}_{5}$, cambio de temperatura del agua, $\mathrm{PO}_{4}{ }^{3-}-\mathrm{P}, \mathrm{NO}_{3}{ }^{-} \mathrm{N}$, turbiedad y TDS. La clasificación del primero se basó en el total de puntos obtenidos por cada uno de los parámetros según el cuadro 3. El segundo consistió en la suma de los productos de los valores $\mathrm{Q}$, obtenido interpolando en la curva de calidad de cada parámetro de acuerdo con su concentración, y el factor de ponderación (w) del cuadro 4, El resultado final se multiplicó por un factor de 1,11 debido que se usó ocho parámetros en vez de nueve, excluyendo el cambio de temperatura del agua.

El agua de la quebrada Victoria se clasificó según su grado de dureza total como carbonato de calcio $\left(\mathrm{CaCO}_{3}\right)$ de acuerdo con el cuadro 5 (Alvarado et al. 2000). Se calculó utilizando la media anual de los resultados de calcio y magnesio.

\section{CUADRO 1}

Clasificación de la calidad del agua según el IHCA-CR

\begin{tabular}{ccll}
\hline Clase & Puntaje & Grado de contaminación & \multicolumn{1}{c}{ Color } \\
\hline 1 & $<3$ & Sin contaminación & Azul \\
2 & $4-6$ & Contaminación Incipiente & Verde \\
3 & $7-9$ & Contaminación moderada & Amarillo \\
4 & $10-12$ & Contaminación severa & Anaranjado \\
5 & $13-15$ & Contaminación muy severa & Rojo
\end{tabular}

CUADRO 2

Clasificación de la calidad del agua según el ICA-U.S.NSF

\begin{tabular}{cll}
\hline Puntaje & \multicolumn{1}{c}{ Calidad del agua } & \multicolumn{1}{c}{ Color } \\
\hline $91-100$ & Excelente & Azul \\
$71-90$ & Buena & Verde \\
$51-70$ & Media & Amarillo \\
$26-50$ & Mala & Anaranjado \\
$0-25$ & Muy mala & Rojo
\end{tabular}

CUADRO 3

Asignación de puntos por parámetro según el IHCA-CR

\begin{tabular}{cccc}
\hline Punto & PSO (\%) & $\mathrm{DBO}_{5}\left(\mathrm{mgL}^{-1}\right)$ & $\mathrm{NH}_{4}{ }^{+}-\mathrm{N}\left(\mathrm{mgL}^{-1}\right)$ \\
\hline 1 & $91-100$ & $\leq 3$ & $<0,50$ \\
2 & $71-90 ; 111-120$ & $3,1-6,0$ & $0,50-1,0$ \\
3 & $51-70 ; 121-130$ & $6,1-9,0$ & $1,1-2,0$ \\
4 & $31-50$ & $9,1-15$ & $2,1-5,0$ \\
5 & $\leq 30 y>130$ & $>15$ & $>5,0$
\end{tabular}

CUADRO 4

Factor de ponderación para los parámetros del ICA-U.S.NSF

\begin{tabular}{lc}
\hline \multicolumn{1}{c}{ Parámetro } & $\begin{array}{c}\text { Factor de } \\
\text { ponderación }\end{array}$ \\
\hline $\begin{array}{l}\text { Porcentaje de saturación de oxígeno } \\
\text { disuelto (\%) }\end{array}$ & 0,17 \\
Coliformes fecales (NMP100 $\left.\mathrm{mL}^{-1}\right)$ & 0,16 \\
$\mathrm{pH}$ (unidades) & 0,11 \\
Demanda bioquímica de oxígeno $\left(\mathrm{mgL}^{-1}\right)$ & 0,11 \\
Cambio de temperatura $\left({ }^{\circ} \mathrm{C}\right)$ & 0,10 \\
Fosfatos totales $\left(\mathrm{PO}_{4}{ }^{3-}-{\left.\mathrm{P} \mathrm{mL}^{-1}\right)}^{-1}\right)$ & 0,10 \\
Nitratos $\left(\mathrm{NO}_{3}{ }^{-}, \mathrm{mgL}^{-1}\right)$ & 0,10 \\
Turbiedad $\left(\mathrm{UNT}^{-}\right)$ & 0,08 \\
Sólidos disueltos $\left(\mathrm{mgL}^{-1}\right)$ & 0,07 \\
&
\end{tabular}

CUADRO 5

Clasificación del agua según su dureza total como carbonato de calcio

\begin{tabular}{cll}
\hline $\begin{array}{c}\text { Concentración en } \\
\mathrm{mgL}^{-1} \text { como CaCO3 }\end{array}$ & Grado de dureza total & Color \\
\hline $0-60$ & Blanda & Morado \\
$61-120$ & Moderadamente dura & Verde \\
$121-180$ & Dura & Amarillo \\
$>180$ & Muy dura & Rojo
\end{tabular}


El agua de la quebrada Victoria se caracterizó geoquímicamente utilizando la media de los resultados de los dos muestreos de la época seca y empleando el programa Aquachem 4.0.272 (Waterloo Hydrogeologic 2003). La clasificación se realizó a partir de la relación de aniones $\left(\mathrm{HCO}_{3}{ }^{-}, \mathrm{Cl}^{-}\right.$y $\left.\mathrm{SO}_{4}{ }^{2-}\right)$ y cationes mayoritarios $\left(\mathrm{Na}^{+}, \mathrm{Ca}^{2+}\right.$ y $\mathrm{Mg}^{2+}$ ) en los siguientes tipos de agua: sulfatada cálcica $\left(\mathrm{SO}_{4}{ }^{2-} / \mathrm{Ca}^{2+}\right)$; sulfatada cálcica-magnésica $\left(\mathrm{SO}_{4}{ }^{2-} / \mathrm{Ca}^{2+} \mathrm{Mg}^{2+}\right)$; o mezclas de agua sulfatada $\left(\mathrm{SO}_{4}{ }^{2-} \mathrm{HCO}_{3}{ }^{-} / \mathrm{Ca}^{2+} \mathrm{Mg}^{2+}\right.$ y $\mathrm{SO}_{4}{ }^{2-}$ $\left.\mathrm{HCO}_{3}{ }^{-} \mathrm{Cl} / \mathrm{Ca}^{2+} \mathrm{Mg}^{2+} \mathrm{Na}+\right)$ y hidrogenocarbonatada $\left(\mathrm{HCO}_{3}{ }^{-}\right.$ $\mathrm{SO}_{4}{ }^{2-} / \mathrm{Ca}^{2+} \mathrm{Mg}^{2+}$ y $\left.^{2} \mathrm{HCO}_{3}{ }^{-} \mathrm{SO}_{4}{ }^{2-} / \mathrm{Ca}^{2+} \mathrm{Mg}^{2+} \mathrm{Na}^{+}\right)$.

\section{Análisis estadístico}

La normalidad de los resultados de los parámetros fue analizada aplicando la prueba estadística de Shapiro-WiIks, modificado por Mahibbur y Govindarajulu en 1997, y utilizando el programa de InfoStat versión 1.1 Universidad Nacional de Córdoba 2002. La hipótesis nula (Ho) planteada fue: los datos siguen una distribución normal.

Para la homocedasticidad de las varianzas se empleó la prueba de Levene, la cual consistió en efectuar el análisis de varianza a los valores absolutos de los residuos de cada

CUADRO 6

Puntaje obtenido de la aplicación del IHCA-CR a la quebrada Victoria, 2007-2008

\begin{tabular}{cccccc}
\hline Sitio & $\begin{array}{c}\text { I época } \\
\text { Iluviosa }\end{array}$ & $\begin{array}{c}\text { II época } \\
\text { Iluviosa }\end{array}$ & $\begin{array}{c}\text { I } \\
\text { época } \\
\text { seca }\end{array}$ & $\begin{array}{c}\text { II } \\
\text { época } \\
\text { seca }\end{array}$ & $\begin{array}{c}\text { Transición } \\
\text { seca a } \\
\text { lluviosa }\end{array}$ \\
\hline 1 & 4 & 3 & 3 & 3 & 3 \\
2 & 4 & 3 & 3 & 3 & 3 \\
3 & 4 & 3 & 3 & 3 & 3 \\
4 & 4 & 3 & 3 & 3 & 4 \\
5 & 5 & 5 & 5 & 5 & 5 \\
6 & 4 & 3 & 4 & 4 & 4 \\
7 & 4 & 4 & 4 & 4 & 4 \\
8 & 4 & 3 & 3 & 3 & 3 \\
9 & 4 & 4 & 4 & 4 & 4 \\
10 & 4 & 3 & 3 & 3 & 3 \\
11 & 4 & 3 & 3 & 3 & 4 \\
12 & 4 & 3 & 3 & 3 & 3 \\
13 & 5 & 4 & 5 & 4 & 5 \\
14 & 4 & 3 & 4 & 3 & 4 \\
15 & 5 & 5 & 5 & 5 & 6 \\
& & & & &
\end{tabular}

parámetro y las épocas de muestreo como variable de clasificación. La Ho fue: las varianzas de las poblaciones son iguales.

Si no se rechazan las dos hipótesis anteriores se aplica el análisis de varianza, de lo contrario se usa la prueba no paramétrica de Kruskal-Wallis para la siguiente Ho: hay diferencias significativas en los parámetros indicadores de calidad del agua de la quebrada Victoria entre las épocas de muestreo: Iluviosa de 2007, seca y transición seca a lluviosa de 2008.

\section{RESULTADOS}

\section{Parámetros e índices de calidad del agua}

Los resultados de los parámetros físico-químicos y bacteriológicos del agua de la quebrada Victoria obtenidos en cada uno de los muestreos se presentan en los Apéndices 1,2 y 3 . Se reporta la incertidumbre media, la media y desviación estándar de cada parámetro. Los resultados de la aplicación del IHCA-CR y el ICA-U.S.NSF al agua de la quebrada se muestran en los cuadros 6 y 7.

\section{CUADRO 7}

Puntaje obtenido de la aplicación del ICA-U.S.NSF a la quebrada Victoria, 2007-2008

\begin{tabular}{|c|c|c|c|c|c|}
\hline Sitio & $\begin{array}{l}\text { I época } \\
\text { Iluviosa }\end{array}$ & $\begin{array}{l}\text { Il época } \\
\text { Iluviosa }\end{array}$ & $\begin{array}{c}\text { I } \\
\text { época } \\
\text { seca }\end{array}$ & $\begin{array}{c}\text { II } \\
\text { época } \\
\text { seca }\end{array}$ & $\begin{array}{c}\text { Transición } \\
\text { seca a } \\
\text { lluviosa }\end{array}$ \\
\hline 1 & 79 & 84 & 86 & 87 & 78 \\
\hline 2 & 80 & 82 & 84 & 87 & 85 \\
\hline 3 & 73 & 75 & 79 & 85 & 73 \\
\hline 4 & 72 & 70 & 79 & 85 & 73 \\
\hline 5 & 76 & 74 & 70 & 75 & 64 \\
\hline 6 & 81 & 78 & 83 & 86 & 80 \\
\hline 7 & 78 & 84 & 84 & 84 & 76 \\
\hline 8 & 85 & 79 & 88 & 81 & 81 \\
\hline 9 & 86 & 74 & 82 & 66 & 78 \\
\hline 10 & 87 & 80 & 86 & 76 & 79 \\
\hline 11 & 79 & 79 & 82 & 80 & 77 \\
\hline 12 & 86 & $*$ & 85 & 82 & 78 \\
\hline 13 & 82 & 79 & 78 & 76 & 69 \\
\hline 14 & 86 & 84 & 83 & 83 & 78 \\
\hline 15 & 83 & 86 & 82 & 82 & 80 \\
\hline
\end{tabular}


El grado de contaminación más alto de la quebrada Victoria, según el IHCA-CR, fue en el primer muestreo de la época lluviosa de 2007, en la cual todos los sitios presentaron contaminación incipiente como se muestra en el recuadro I de la figura 3. A partir del segundo muestreo de la época lluviosa disminuyó (recuadro Il con $33 \%$ de los sitios) $y$, posteriormente, se incrementó en los siguientes dos muestreos de la época seca (recuadro III con $47 \%$ de los sitios; recuadro IV con $40 \%$ de los sitios) hasta la época de transición seca a lluviosa (recuadro V con $60 \%$ de los sitios).

La calidad del agua de la quebrada Victoria, según el ICAU.S.NSF, se mantuvo en buena en todas las épocas de muestreo como se muestra en la figura 4, con la excepción de un caso puntual en los siguientes cuatro muestreos (sitio 4 del recuadro II, sitio 5 del recuadro III, sitio 9 del recuadro IV y sitio 5 del recuadro $V$ ) que se deterioró a una calidad media.
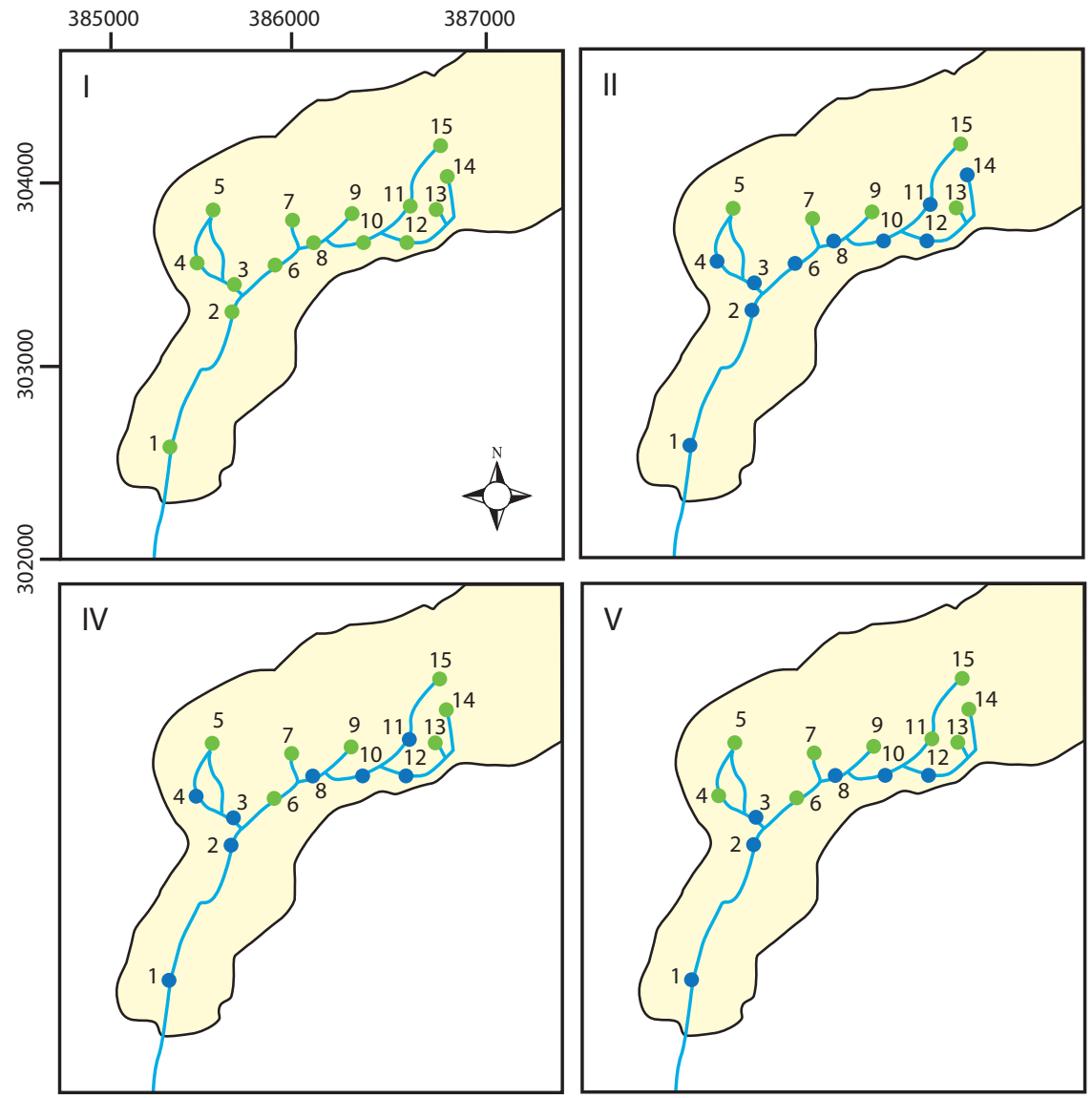

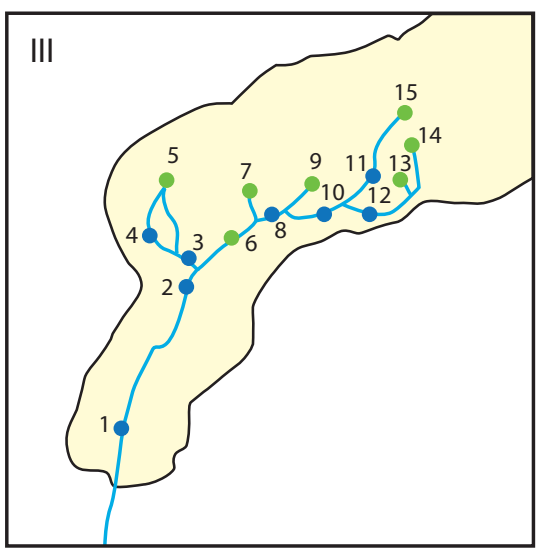

Indice de calidad del agua

- $<3$ Sin contaminación

- 4-6 Contaminación incipiente

- 7-9 Contaminación moderada

-10-12 Contaminación severa

-13-15 Contaminación muy severa

I Primer muestreo época lluviosa

II Segundo muestreo época lluviosa

III Primer muestreo época seca

IV Segundo muestreo época seca

$\checkmark$ Época de transición seca a lluviosa

1-15 Sitios de muestreo

— Quebrada Victoria

$\square$ Microcuenca de la quebrada

FIG. 3. Clasificación del agua de la quebrada Victoria, 2007-2008, según el índice holandés de calidad del agua. 


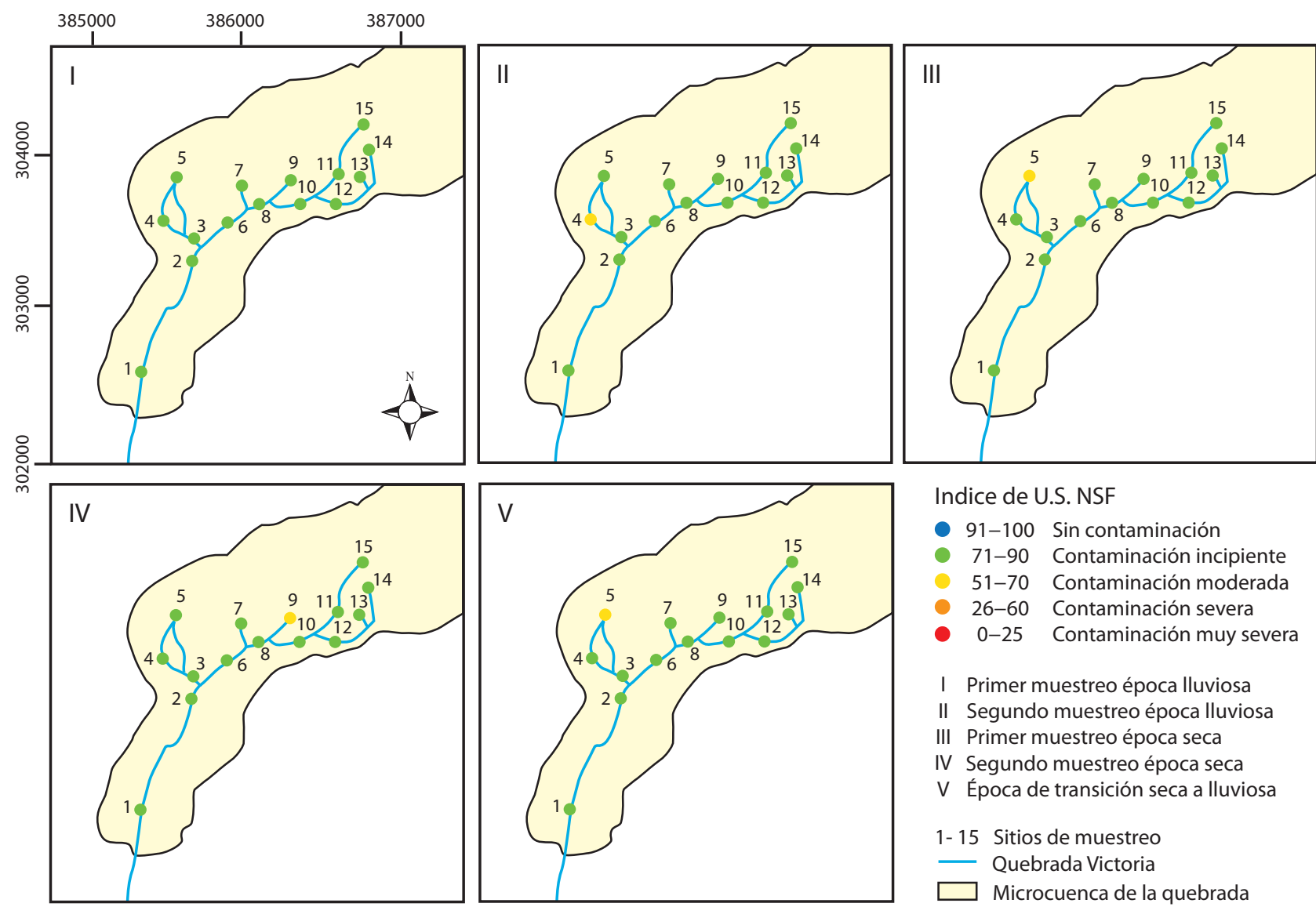

FIG. 4. Clasificación del agua de la quebrada Victoria, 2007-2008, según el índice de calidad del agua de la U.S.NSF.

Sin dato: sitio 12 del recuadro II.

\section{Caracterización química}

El agua de la quebrada Victoria según su dureza total como $\mathrm{CaCO}_{3}$ se clasificó en moderadamente dura y blan$\mathrm{da}$, como se muestra en la figura 5 . El $87 \%$ de los sitios presentaron una media anual entre $68 \mathrm{mgL}^{-1}$ y $82 \mathrm{mgL}^{-1}$ de $\mathrm{CaCO}_{3}$ y el $13 \%$ de los sitios entre $33 \mathrm{mgL}^{-1}$ y $52 \mathrm{mgL}^{-1}$ de $\mathrm{CaCO}_{3}$.

El tipo de agua que predominó en la quebrada Victoria, según su caracterización geoquímica, en la época seca de 2008 fue la sulfatada cálcica-magnésica (47\% de los sitios), seguida de la sulfatada cálcica ( $27 \%$ de los sitios) y el restante ( $26 \%$ de los sitios) en mezclas de aguas sulfatadas y hidrogenocarbonatadas, como se presenta en la figura 6,

\section{Análisis estadístico}

Los resultados de los parámetros, con la excepción del $\mathrm{Cl}^{-}, \mathrm{Na}^{+}, \mathrm{Mg}^{2+}, \mathrm{F}^{-}$y temperatura del agua, no siguieron una distribución normal, según la prueba de Shapiro-Wilks modificado por Mahibbur y Govindarajulu en 1997, como se presenta en el cuadro 8. La prueba de Levene indicó que las varianzas de la mayoría de las poblaciones de los datos no son iguales. Por lo anterior, se aplicó la prueba no paramétrica de Kruskal-Wallis, obteniendo el siguiente resultado: no se rechaza la hipótesis nula para los parámetros de turbiedad, oxígeno disuelto y coliformes fecales; $y$ se rechaza para los demás parámetros al $5 \%$ de significación. Los datos cuyos resultados estuvieron por debajo de 


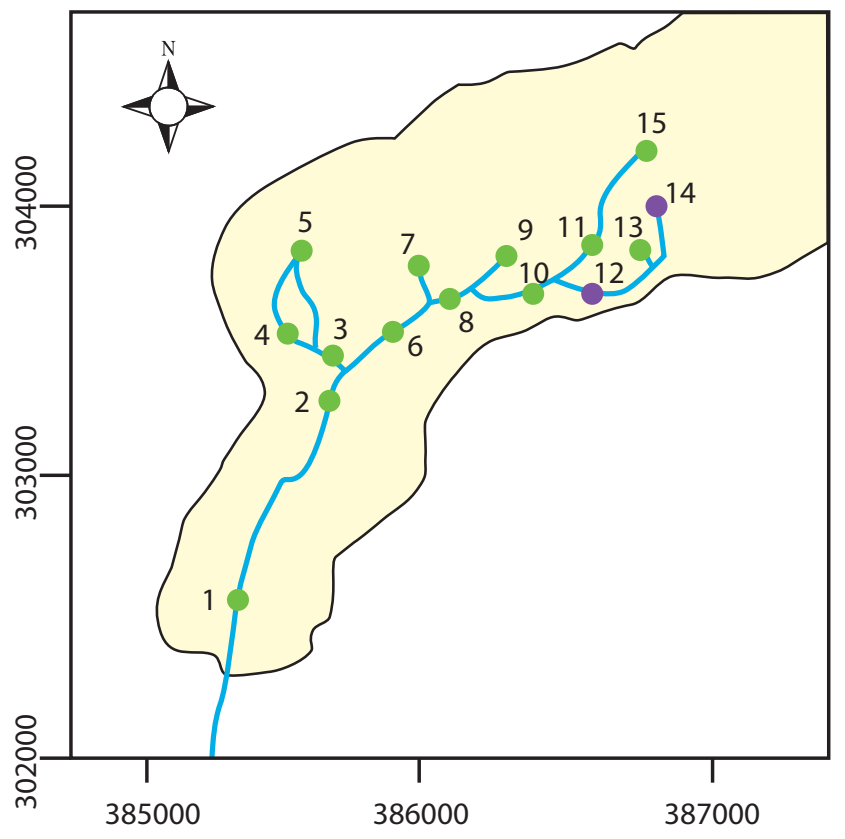

$\mathrm{CaCO}_{3} \quad$ Grado de dureza (mg/L)

Sin contaminación

71-90 Contaminación incipiente

51-70 Contaminación moderada

26-60 Contaminación severa

FIG. 5. Clasificación del agua de la quebrada Victoria según su dureza total media anual, 2007-2008.

sus límites de cuantificación no se aplicaron estas pruebas

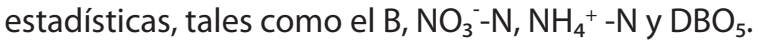

\section{DISCUSIÓN}

\section{Evaluación de la calidad del agua}

Los índices de calidad del agua permite la valoración general del cuerpo de agua mostrando la variación espacial y temporal por medio de una fácil interpretación de categorías.

El deterioro en la calidad del agua, según el IHCA-CR, de la quebrada Victoria en la época lluviosa (recuadro I de la figura 3) y de transición seca a lluviosa (recuadro V), indica que puede comprometer la vida acuática.

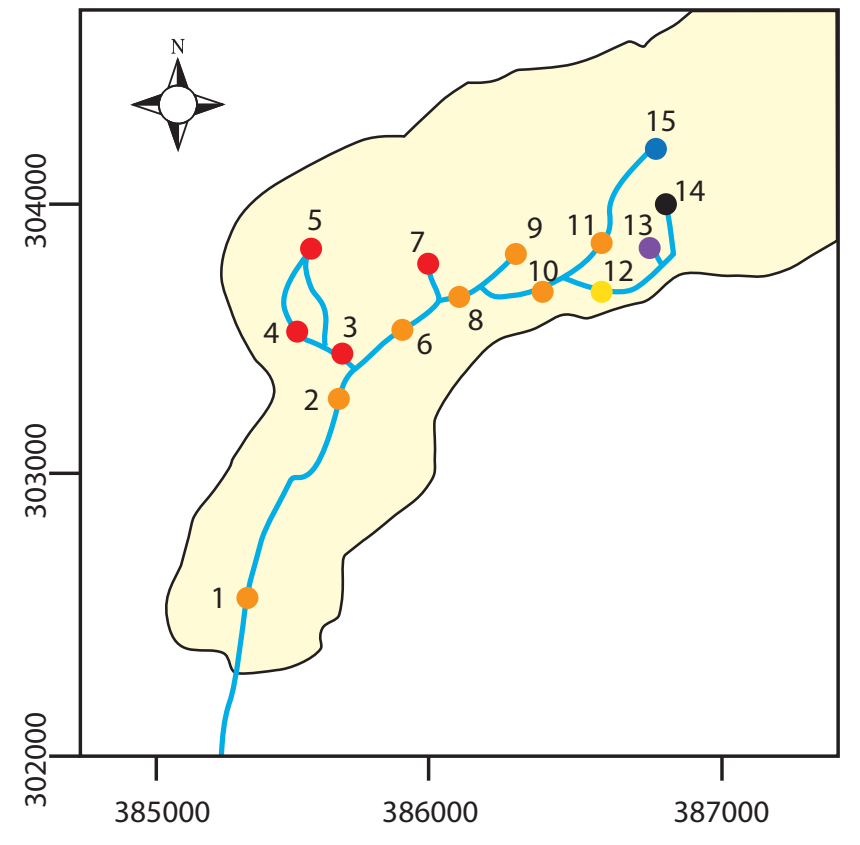

Tipo de agua según caracterización geoquímica
$\frac{\mathrm{SO}_{4}^{2-}}{\mathrm{Ca}^{2+}}$
$\frac{\mathrm{SO}_{4}{ }^{2-} \mathrm{HCO}_{3}{ }^{-}}{\mathrm{Ca}^{2+} \mathrm{Mg}^{2+}}$
$\frac{\mathrm{HCO}_{3}{ }^{-} \mathrm{SO}_{4}{ }^{2-}}{\mathrm{Ca}^{2+} \mathrm{Mg}^{2+}}$
$\frac{\mathrm{SO}_{4}^{2-}}{\mathrm{Ca}^{2+} \mathrm{Mg}^{2+}}$
$\frac{\mathrm{SO}_{4}{ }^{2-} \mathrm{HCO}_{3} \mathrm{Cl}^{-}}{\mathrm{Ca}^{2+} \mathrm{Mg}^{2+} \mathrm{Na}^{+}}$
$\frac{\mathrm{HCO}_{3} \mathrm{SO}_{4}^{2-}}{\mathrm{Ca}^{2+} \mathrm{Mg}^{2+} \mathrm{Na}^{+}}$

FIG. 6, Clasificación del agua de la quebrada Victoria según su caracterización geoquímica en la época seca de 2008.

Esta degradación mejora en la época seca (recuadros III y IV), cambiando de un grado de contaminación incipiente a uno sin contaminación, en los sitios a lo largo de la quebrada.

Al segregar el IHCA-CR, se encuentran que los resultados de la $\mathrm{DBO}_{5}$ y el $\mathrm{NH}_{4}{ }^{+}-\mathrm{N}$ indican que la contaminación por materia orgánica y nitrogenada es baja. El parámetro que contribuyó al deterioro de este índice fue el PSO, el cual según el análisis estadístico (Cuadro 8), difieren entre las épocas de muestreo, lo que explica su variación estacional. La disminución del PSO en las nacientes (Apéndice 2) concuerda con valores bajos de caudal en la época seca, debido a una menor aireación del medio.

El aumento del PSO a lo largo de la quebrada (recuadros II, III y IV de la figura 3) en comparación con las nacientes justifica la variabilidad espacial del índice. Este 
CUADRO 8

Resultados de la aplicación de las pruebas estadísticas a los datos obtenidos de la quebrada Victoria

\begin{tabular}{c|cccccc}
\hline \multirow{2}{*}{ Parámetro } & $\begin{array}{c}\text { Prueba de Shapiro- } \\
\text { Wilks }\end{array}$ & \multicolumn{2}{c}{ Prueba de Levene } & $\begin{array}{c}\text { Prueba no paramétrica } \\
\text { de Kruskal-Wallis }\end{array}$ \\
\cline { 2 - 6 } & W & p-valor & F & p-valor & H & p-valor \\
\hline PSO & 0,78 & $<0,0001$ & 7,44 & 0,0013 & 6,18 & 0,0450 \\
CF & 0,46 & $<0,0001$ & 1,52 & 0,2275 & 6,30 & 0,0414 \\
pH & 0,84 & $<0,0001$ & 0,18 & 0,8349 & 0,93 & 0,6275 \\
Turbiedad & 0,81 & $<0,0001$ & 11,91 & $<0,0001$ & 9,56 & 0,0084 \\
TDS & 0,94 & 0,0060 & 0,17 & 0,8455 & 1,63 & 0,4430 \\
Dureza total & 0,85 & $<0,0001$ & 2,22 & 0,1176 & 3,23 & 0,1979 \\
$\mathrm{HCO}_{3}^{-}$ & 0,86 & $<0,0001$ & 4,97 & 0,0103 & 0,06 & 0,9694 \\
$\mathrm{Cl}^{-}$ & 0,97 & 0,3578 & 5,85 & 0,0049 & 2,68 & 0,2620 \\
$\mathrm{SO}_{4}{ }^{2-}$ & 0,92 & 0,0010 & 3,62 & 0,0333 & 1,96 & 0,3745 \\
$\mathrm{Na}^{+}$ & 0,95 & 0,0195 & 5,86 & 0,0049 & 2,99 & 0,2225 \\
$\mathrm{Ca}^{2+}$ & 0,84 & $<0,0001$ & 0,35 & 0,7082 & 5,39 & 0,0670 \\
$\mathrm{Mg}^{2+}$ & 0,98 & 0,7388 & 1,55 & 0,2202 & 0,09 & 0,9575 \\
$\mathrm{~F}^{-}$ & 0,96 & 0,1655 & 2,34 & 0,1060 & 2,48 & 0,2896 \\
$\mathrm{TH}_{2} \mathrm{O}$ & 0,97 & 0,5752 & 1,66 & 0,1996 & 3,16 & 0,2045 \\
$\mathrm{CE}^{-}$ & 0,94 & 0,0060 & 0,26 & 0,7703 & 5,51 & 0,0635 \\
$\mathrm{Caudal}^{-}$ & 0,81 & $<0,0001$ & 24,64 & $<0,0001$ & 5,64 & 0,0596
\end{tabular}

aumento coincide con el incremento del caudal en la quebrada (Apéndice 1) en el segundo muestreo de la época lluviosa, que conlleva a una mayor aireación del sistema y mejora el índice, situación que se mantiene en la época seca. Este comportamiento concuerda con lo encontrado por Calvo y Mora (2007) en los ríos Tárcoles y Reventazón de Costa Rica.

La calidad del agua de la quebrada Victoria es buena, según el ICA-U.S.NSF. Dicho índice ha sido aplicado en México en la cuenca del río Amajac obteniendo una calidad media y mala (Alvarez et al. 2006). En Oregon de los Estados Unidos, este índice fue modificado por Cude (2001), agregando el amoniaco al nitrato, como una herramienta comunicativa sobre la calidad general del agua y es aplicable para todos los usos. En Costa Rica, se ha aplicado, excluyendo el pH y TDS y con una clasificación asociada al grado de contaminación (Peinador 2004), para correlacionarlo con macroinvertebrados como bioindicadores en 33 ríos del país, dentro de los cuales el más cercano a la microcuenca en estudio fue el de Liberia que se clasificó en una categoría de aguas muy contaminadas.
De los cinco muestreos efectuados, cuatro presentaron un caso puntual de deterioro en la calidad del agua de la quebrada, de buena a media, en los sitios 4, 5 y 9 (recuadros II, III, IV y V de la figura 4). Por esto, es necesario segregar el ICA-U.S.NSF para analizar detalladamente sus parámetros e identificar los que están siendo afectados por los cambios en su calidad. Los parámetros que difieren entre las épocas de muestreo, según el análisis estadístico (cuadro 8), fueron la turbiedad, el PSO y los CF.

Los sitios 5 y 9 son nacientes, por lo que en relación con el PSO, presentan el mismo comportamiento que el observado en el IHCA-CR. El incremento tanto de los CF como la turbiedad en los sitios 4 y 9 coincide con el aumento del caudal (Apéndices 1, 2 y 3) en la época lluviosa y de transición seca a lluviosa.

Otro parámetro que contribuyó al deterioro de la calidad, según el ICA-U.S.NSF, fue el pH del sitio 5, el cual se caracterizó por ser ácido (entre 3,90 y 9,17). Esta condición es natural de la naciente, por lo que no es adecuado incluirse en el índice para el seguimiento de efectos de 
actividades humanas debido a la variabilidad geológica de cada cuenca (Cude 2001). Su inclusión es útil para analizar tendencias en una misma cuenca, pero no para hacer comparaciones espaciales.

Es importante destacar que el ICA-U.S.NSF fue desarrollado para cuerpos de agua frías y en donde hay diferencias estacionales bien marcadas, por lo tanto, parámetros como el cambio de temperatura y el PSO afectan la reproducción de las especies acuáticos y los requerimientos mínimos para su supervivencia (Cude 2001, Smith et al. 2002). En este caso, por estar la quebrada influenciada por el desarrollo geotérmico, el cambio de temperatura del agua es un parámetro importante para detectar contaminación térmica considerando como referencia la temperatura media anual $\left(25,0^{\circ} \mathrm{C}\right)$.

El IHCA-CR categoriza los cuerpos de agua superficiales según su grado de contaminación de acuerdo con el contenido de contaminación orgánica y nitrogenada, cuyo efecto en el sistema acuático se evalúa mediante el PSO. Estas condiciones se reflejan en las aguas superficiales que reciben descargas de aguas residuales productos de las actividades humanas, como los sitios evaluados por Calvo \& Mora (2007).

En cuanto al ICA-U.S.NSF en la quebrada Victoria, no se observaron diferencias significativas, según el análisis estadístico (cuadro 8), en la $\mathrm{DBO}_{5}, \mathrm{PO}_{4}{ }^{3-}-\mathrm{P}, \mathrm{NO}_{3}{ }^{-} \mathrm{N}$ y TDS. $\mathrm{La}$ conductividad del agua da una apreciación de la concentración de los iones en disolución y está relacionada con el TDS (Orozco et al. 2005). Además, su medición es rápida y sencilla en comparación con el TDS. Por estas razones, se sugiere incluir la conductividad, la cual se incluyó en el índice desarrollado por Pérez-Castillo y Rodríguez (2008), en los programas de seguimiento de calidad del agua.

\section{Caracterización química del agua}

El consumo de agua dura, de más de $120 \mathrm{mgL}^{-1}$ de $\mathrm{CaCO}_{3}$, está asociado con el riesgo de padecer cálculos de las vías urinarias inferiores y se han encontrado casos en las provincias de Guanacaste y Puntarenas de Costa Rica (Alvarado et al. 2000). Además, se ha reportado hasta el 2004 en Curubandé enfermedades de riñones y de las vías urinarias (ICE 2005). Por estas razones y debido a que el acueducto de este distrito se encuentra en la quebrada Victoria, se debe mantener la vigilancia y seguimiento de la calidad de esta agua, que se caracteriza por ser moderadamente dura (Fig. 5).

Las sustancias tóxicas, como boro y fluoruro, no fueron incluidas en los índices evaluados, por lo que deben ser evaluados individualmente previo al análisis de los índices. Pérez-Castillo \& Rodríguez (2008) desarrollaron uno similar al ICA-U.S.NSF pero que se fija automáticamente en cero, si la concentración de alguna sustancia tóxica excede el límite máximo permisible. Esto permite emitir una alarma de acción inmediata al gestor del recurso hídrico.

Los valores de boro encontrados en el agua de la quebrada Victoria estuvieron por debajo de $0,1 \mathrm{mgL}^{-1}$, el cual, en caso de ser utilizado para el riego, no compromete a los cultivos sensibles, semitolerante y tolerantes, cuyos límites máximos son de $0,3 \mathrm{mgL}^{-1}, 0,7 \mathrm{mgL}^{-1}$ y $1,0 \mathrm{mgL}^{-1}$, respectivamente (Custodio \& Díaz 2001).

Las concentraciones de fluoruro en el agua de la quebrada Victoria estuvieron entre $0,07 \mathrm{mgL}^{-1}$ y $0,57 \mathrm{mgL}^{-1}$, ámbito que se encuentra por debajo de $1,5 \mathrm{mgL}^{-1}$, a partir del cual conlleva a la fluorosis dental y esquelética (Piris da Motta et al. 2003). El contenido encontrado en el agua de la quebrada protege a los consumidores, en este caso de Curubandé, de la aparición de caries dentales, especialmente en niños, siempre y cuando sea menos de $1,0 \mathrm{mgL}^{-1}$ (Sawyer et al. 2001).

El tipo dominante de agua de la quebrada Victoria fue sulfatada cálcica-magnésica (Fig. 6). Los fluidos de los pozos geotérmicos del campo geotérmico Las Pailas (Fig. 1) en condiciones de presión atmosférica son del tipo clorurados sódicos y de alta concentración salina (Chavarría et al. 2006). La química de las aguas termales de las faldas del volcán Rincón de la Vieja se caracteriza por ser clorurada-sulfatada ácida, sulfatada ácida y clorurada neutra (Kempter \& Rowe 2000). Estas aguas tienen propiedades químicas muy diferentes, razón por la cual permite dar seguimiento a su origen si se presentan infiltración o mezclas.

El sitio 12 (Fig. 6) se caracteriza por tener una mezcla de agua tipo sulfatada-hidrogenocarbonatada, que es específica del sitio 13, y de un tipo clorurada sódica, la cual es proveniente de las aguas geotérmicas. Dogdu \& Bayari (2005) detectaron que la calidad físico-química de las aguas superficiales de la cuenca de Akarcay, Turquía, se deterioró por la intrusión de aguas termales durante la producción de pozos en los sitios cercanos a los campos geotérmicos. Esto pudo haber ocurrido con el pozo geotérmico que se encuentra cercano y en la parte alta del sitio 12 (Fig. 1).

Desde el punto de vista geoquímico, el cloruro es un elemento"conservativo", es decir, que tiene largos tiempos de retención y es muy soluble en el agua (Giggenbach \& Goguel 1989), por lo que puede servir como trazador para el seguimiento de derrames o infiltración de fluidos geotérmicos hacia la quebrada. La diferencia en dos órdenes de magnitud en su concentración: las aguas de la quebrada Victoria presentan entre $4,2 \mathrm{mgL}^{-1}$ y $18,7 \mathrm{mgL}^{-1}$ (Apéndices 1,2 y 3); mientras que, las de los pozos geotérmicos entre 
$6000 \mathrm{mgL}^{-1}$ y $7000 \mathrm{mgL}^{-1}$ (ICE 2005), sirve como indicador de una posible contaminación por aguas geotérmicas.

La calidad del agua de la quebrada Victoria se clasificó en una clase 1 (sin contaminación) en la época seca de 2007 y se deterioró a una clase 2 (contaminación incipiente), entre $40 \%$ y $60 \%$ de los sitios, en la época lluviosa de 2007 y de transición seca a lluviosa de 2008, según el índice holandés de calidad del agua del Reglamento costarricense para la evaluación y clasificación de la calidad de cuerpos de agua superficiales (IHCA-CR).

El agua de la microcuenca de la quebrada Victoria fue de calidad buena (entre 71 y 90 puntos), según el índice de la Fundación Nacional de Sanidad de los Estados Unidos (ICA-U.S.NSF), durante el año hidrológico 2007-2008, por lo que fue adecuada para la conservación de sistemas acuáticos.

Para los programas de seguimiento de la calidad del agua de la quebrada Victoria y de efectos del desarrollo geotérmico, como principal actividad en la microcuenca, debe incluir los siguientes indicadores: de contaminación fecal, los coliformes fecales; de calidad física, la turbiedad; del estado de los sistemas acuáticos, el porcentaje de saturación de oxígeno disuelto; del contenido de sales disueltos, la conductividad; de contaminación térmica, la temperatura del agua; de trazador de aguas geotérmicas, el cloruro.

Se recomienda complementar la evaluación de la calidad del agua de la quebrada Victoria con indicadores e índices biológicos para tener una visión completa de la salud del agua y de los sistemas acuáticos.

\section{AGRADECIMIENTOS}

Se agradece al Laboratorio Nacional de Aguas del Instituto Costarricense de Acueductos y Alcantarillados y al Laboratorio de Geoquímica del Instituto Costarricense de Electricidad por su apoyo a la investigación.

\section{REFERENCIAS}

Alvarado, D, N. Alfaro, \& F. Portuguez. 2000. Cálculos en las vías urinarias y su relación con el consumo de calcio en el agua de bebida en Costa Rica. Revista Costarricense de Salud Pública 9:61-70.

Alvarez, A., J. Rubiños, F. Gavi, J. Alarcón, E. Hernández, C. Ramírez, E. Mejía, F. Pedrero, E. Nicolas \& F. Salazar. 2006. Indice de calidad del agua en la cuenca del río Amajac, Hidalgo, México: Diagnóstico y Predicción. International Journal of Experimental Botany 75:71-83.
Arcos, M.P., S.L. Ávila de Navia, S.M. Estupiñán \& A.C. Gómez. 2005. Indicadores microbiológicos de contaminación de las fuentes de agua. Nova Publicación Científica 3: 69-79.

Bianchini, G., M. Pennisi, R. Cioni, A. Muti, N. Cerbi \& W. Kloppmann. 2005. Hydrochemistry of the high-boron groundwaters of the Cornia aquifer (Tuscany, Italy). Geothermics 34:297-319.

Calvo, G. \& J. Mora. 2007. Evaluación y clasificación preliminar de la calidad de agua de la cuenca del río Tárcoles y el Reventazón. Parte III: Calidad de cuerpos receptores de agua, según el Sistema Holandés de Valoración. Tecnología en Marcha 20:59-67.

Chapman, D. 1996. Water Quality Assessment: a Guide to Use of Biota Sediments and Water in Environmental Monitoring. UNESCO, WHO, UNEP. Londres, Reino Unido.

Chavarría, L., P. Mora, E. Hakanson, F. Molina, E. Vega, Y. Torres, O. Vallejos, A. Yock, G. Lezama \& S. Castro. 2006. Miravalles Consulting Panel Meeting Development Strategies of the Pailas Geothermal Field. Instituto Costarricense de Electricidad, Guanacaste, Costa Rica.

Costa Rica. 2007. Reglamento para la evaluación y clasificación de la calidad de cuerpos de agua superficiales. La Gaceta 178:1-7.

Cude, C. 2001. Oregon Water Quality Index: A Tool for Evaluating Water Quality Management Effectiveness. Journal of the American Resources Association 37:125-137.

Custodio, E. \& E. Díaz. 2001. Hidrología Subterránea. Omega, Barcelona, España.

Dogdu, M. \& C. Bayari. 2005. Environmental impact of geotermal fluid son surface water, groundwater and streambed sediments in the Akarcay Basin, Turkey. Environmental Geology 47:352-340.

Eaton, A., L. Clesceri, E. Rice \& A. Greenberg. 2005. Standard Methods for the Examination of Water and Wastewater. Centennial, Washington, EEUU.

Giggenbach, W.F. \& R.L. Goguel. 1989. Collection and Analysis of Geothermal and Volcanic Water and Gas Discharges. Department of Scientific and Industrial Research, Petone, Nueva Zelanda.

IAEA (International Agency Energy Atomic). 2003. A compilation of Laboratory Procedures for the Chemical Analysis of Geothermal Water Samples. Vienna, Austria.

ICE (Instituto Costarricense de Electricidad). 2005. Estudio de impacto ambiental proyecto geotérmico Las Pailas. Tomo I, Expediente SETENA N 788-04, San José, Costa Rica.

INEC (Instituto Nacional de Estadística y Censos). 2002. IX Censo nacional de población: características sociales y demográficas. Instituto Nacional de Estadística y Censos, San José, Costa Rica.

Kempter, K.A. \& Rowe, G.L. 2000. Leakage of Active Crater Lake Brine through the North Flank at Rincon de la Vieja Volcano, Northwest Costa Rica, and Implications for Crater CoIlapse. Journal of Volcanology and Geothermal Research 97:143-159. 
NSF (National Sanitation Foundation). 2007. Water Quality Index. Michigan, US. (http://www.nsf.org/consumer/just_for_ kids/wqi.asp; consultado 22 agosto 2008)

Orozco, B.C., S.A. Pérez, D.M. González, V.F. Rodríguez \& B.J. Alfayate. 2005. Contaminación Ambiental: una visión desde la química. Thomson, Madrid, España.

Peinador, M. 2004. Relación entre los macroinvertebrados bénticos y la calidad del agua en ríos de Costa Rica. Revista Evolución del Instituto Costarricense de Acueductos y Alcantarillados 2:1-23.

Pérez-Castillo, A. \& A. Rodríguez. 2008. Índice fisicoquímico de la calidad de agua para el manejo de lagunas tropicales de inundación. Revista Biología Tropical 56:1905-1918.

Piris da Motta, M.R., C. Zacharzewski, J. Miño, M. Bordenave, L. Rinaldi, P.D. Iurinic, A. Piaggio, M. Morchio, M. Montiel, M.C. Alberto, S. Bracco, M. Koziarski, J.C. Kempski, S. Kuhlmann, G. Freitag, G. Okulovich \& L. Santader. 2003. Influencia de factores socioeconómicos y culturales en la asociación entre índices de caries dental y la fluoruración del agua potable. Congreso Argentino de Saneamiento y Medio Ambiente, 9-11 de setiembre, Buenos Aires, Argentina.

Samboni, N., Y. Carvajal \& J. Escobar. 2007. Revisión de parámetros fisicoquímicos como indicadores de calidad y contaminación del agua. Revista de Ingeniería e Investigación 27:172-181.
Sancha, A.M. \& C. Espinoza. 2001. Determinación de contenido natural e índices de calidad: ¿presente y futuro de calidad de aguas? XIV Congreso Chileno de Ingeniería Sanitaria y Ambiental, 11-14 de octubre, Santiago.

Sawyer, C.N., P.L. McCarty \& G.F. Parking. 2001. Química para ingeniería ambiental. McGraw-Hill, Bogotá, Colombia.

Smith, D., R. Javies-Colley \& J. Nagels. 2002. Oregon Water Quality Index: A Tool for Evaluating Water Quality Management, by Curtis G. Cude. Journal of the American Water Resources Association 38:313-314.

Tassi, F., O. Vaselli, B. Capaccioni, C. Giolito, E. Duarte, E. Fernández, A. Minissale \& G. Magro. 2005. The hydrothermal-volcanic system of Rincon de la Vieja volcano (Costa Rica): A combined (inorganic and organic) geochemical approach to understanding the origin of the fluid discharges and its application to volcanic surveillance. Journal of Volcanology and Geothermal Research 148:315-333.

Waterloo Hydrogeologic. 2003. Aquachem 4.0.272, Waterloo Hydrogeologic, Ontario, Canada.

WWPA (Programa Mundial de evaluación de los Recursos Hídricos, FR). 2003. Primer Informe de las Naciones Unidas sobre el Desarrollo de los Recursos Hídricos en el Mundo. Resumen Ejecutivo. Agua para Todos, Agua para la Vida. (http://www.unesco.org/water/wwap/index_es.shtml; consultado 20 julio, 2007). 


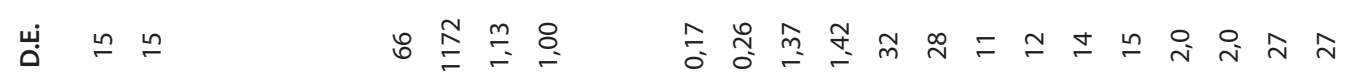

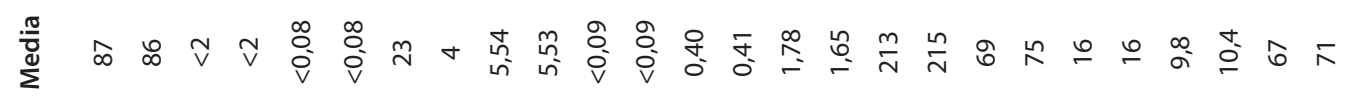

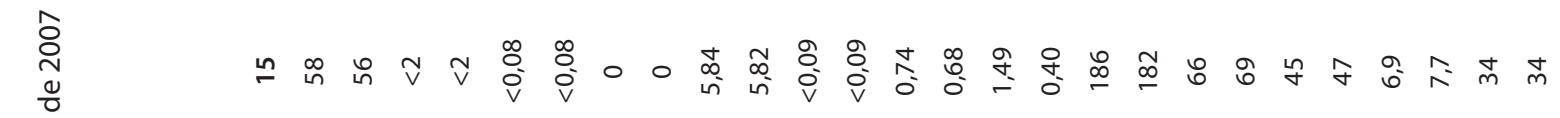

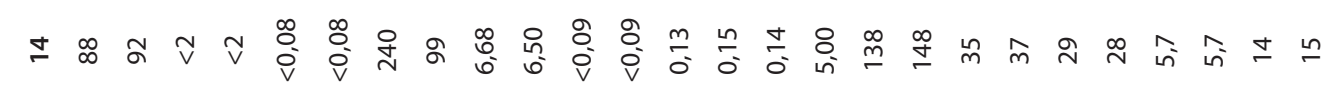

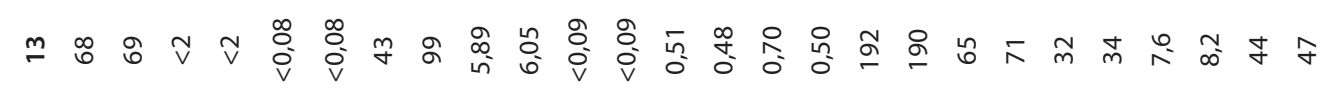

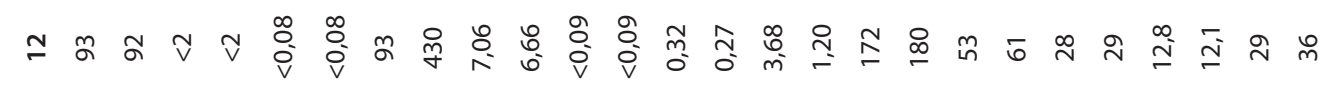

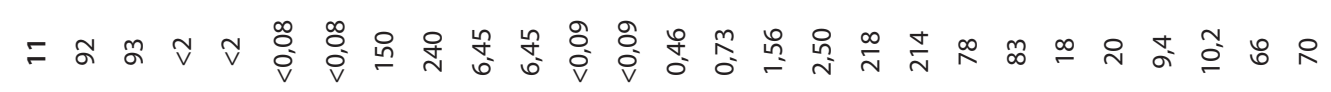
의 $n v \vee$ v ๑

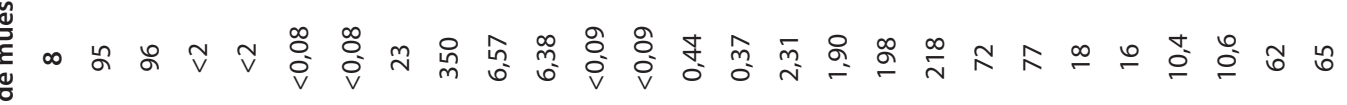

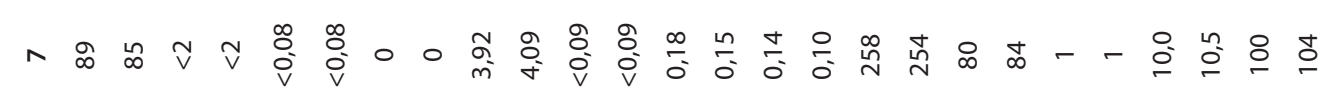

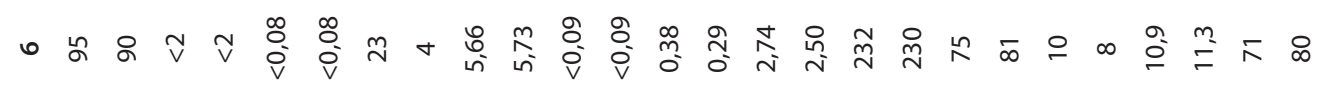

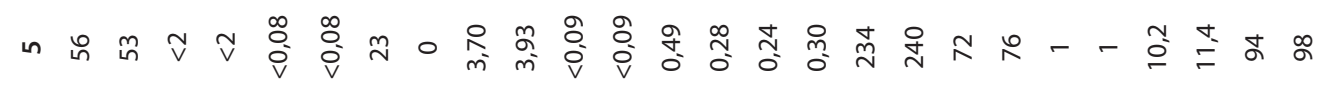
+ 万人 m ๙ o v v

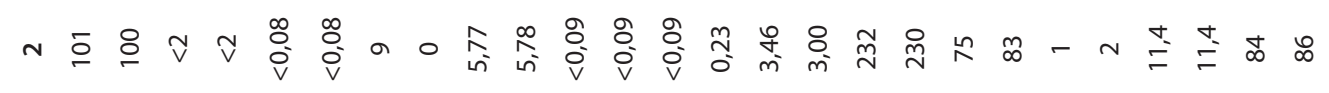

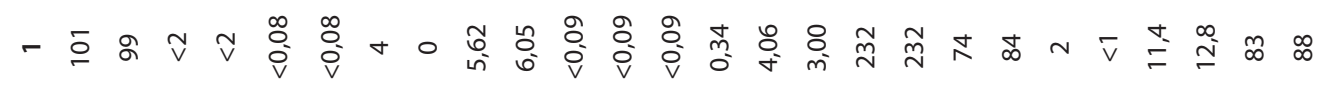
$\sum-=-=-=-=-=-=-=-=-=-=-=-=-=$

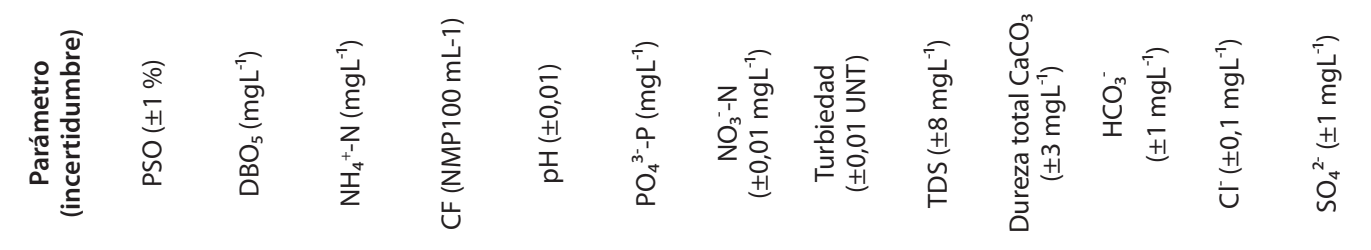




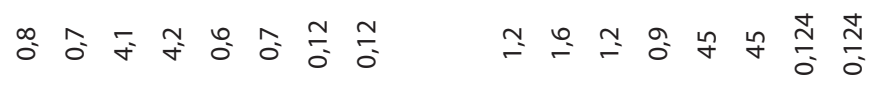

$$
\begin{aligned}
& \text { 읏 - }
\end{aligned}
$$

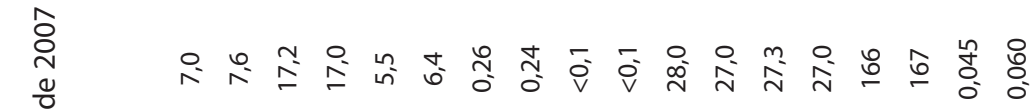

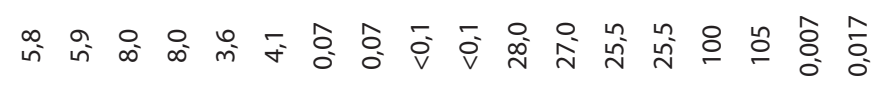

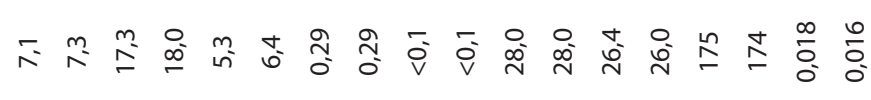

๙2

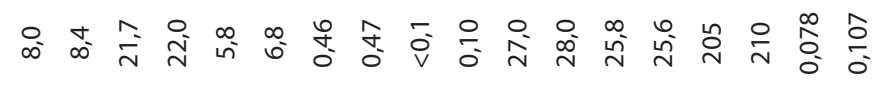

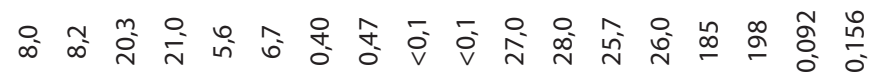

我

क⿻

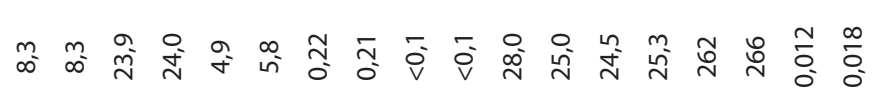

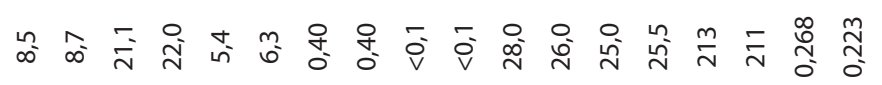

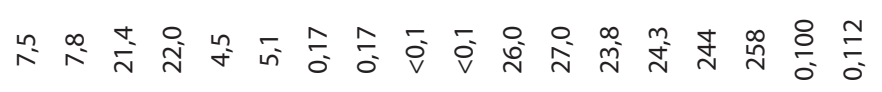

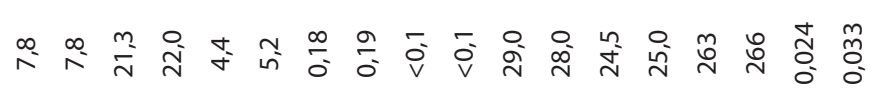

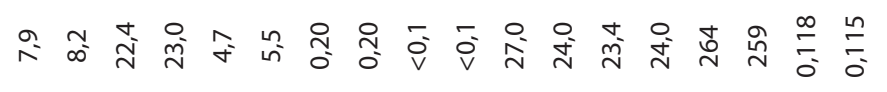

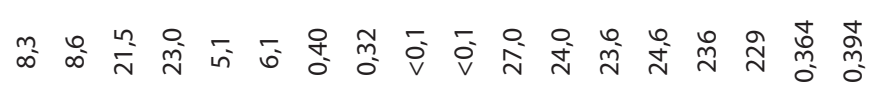

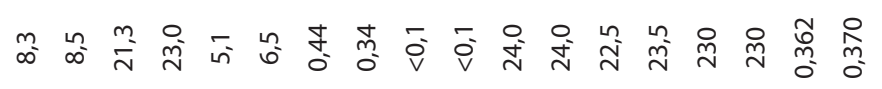

$-=-=-=-=-=-+=-=$

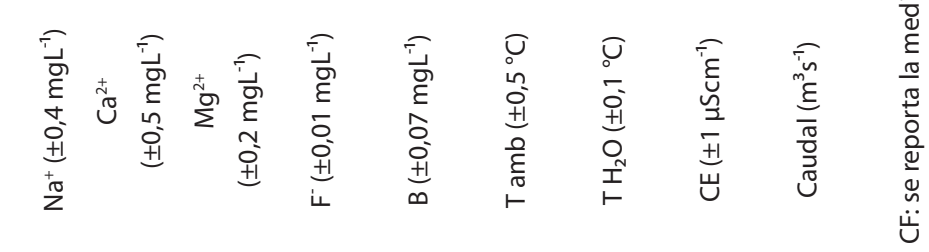




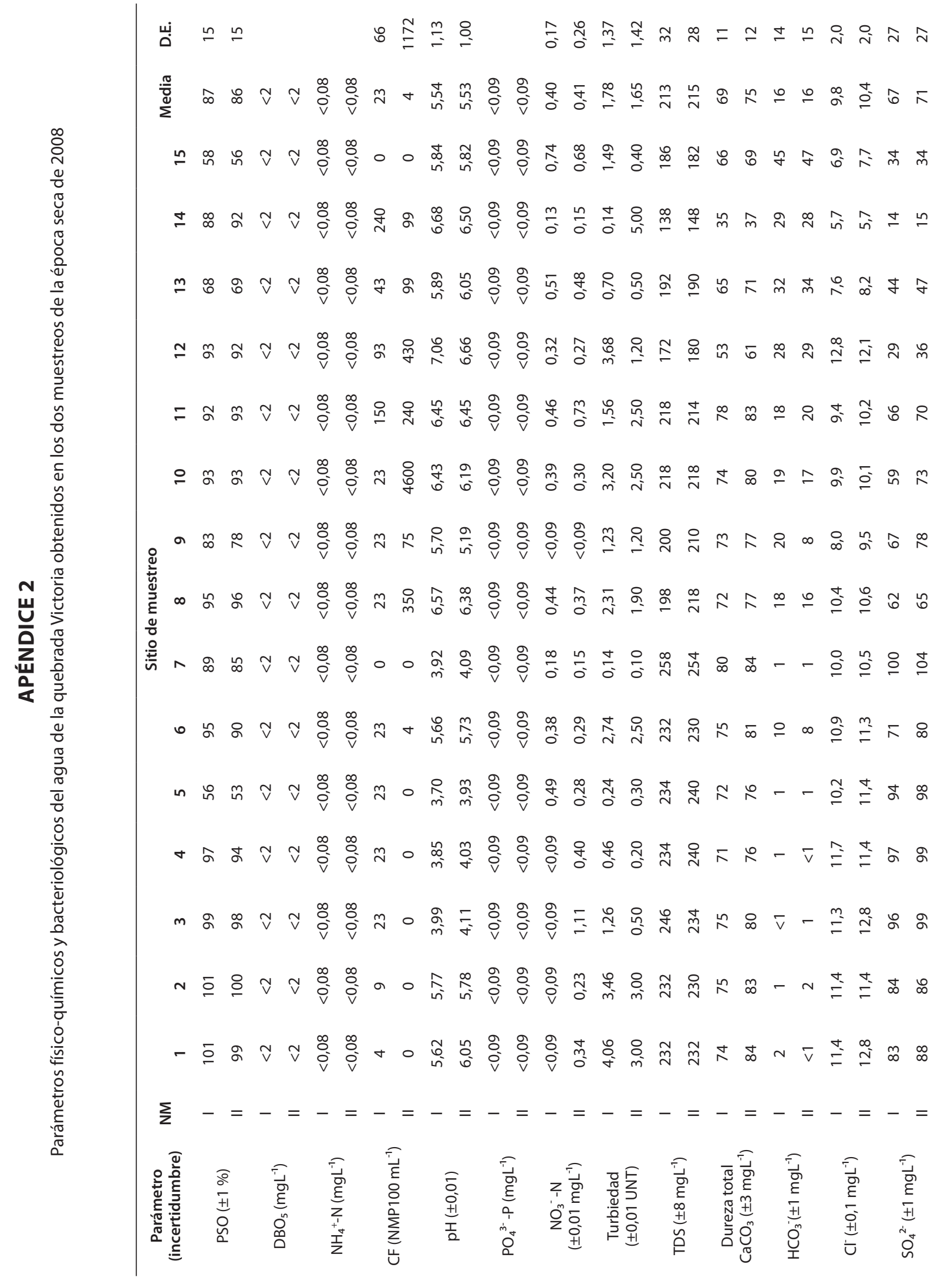




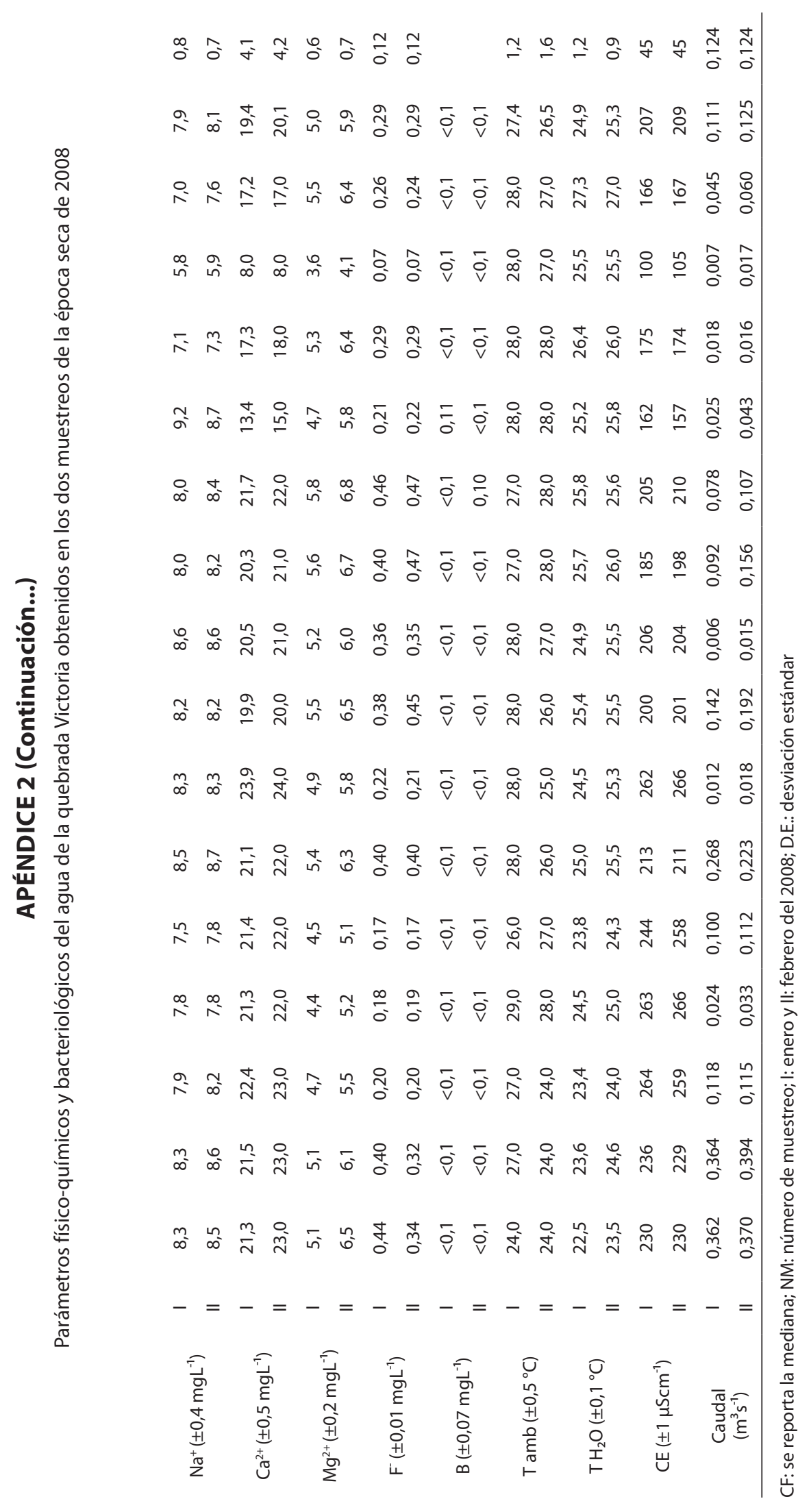




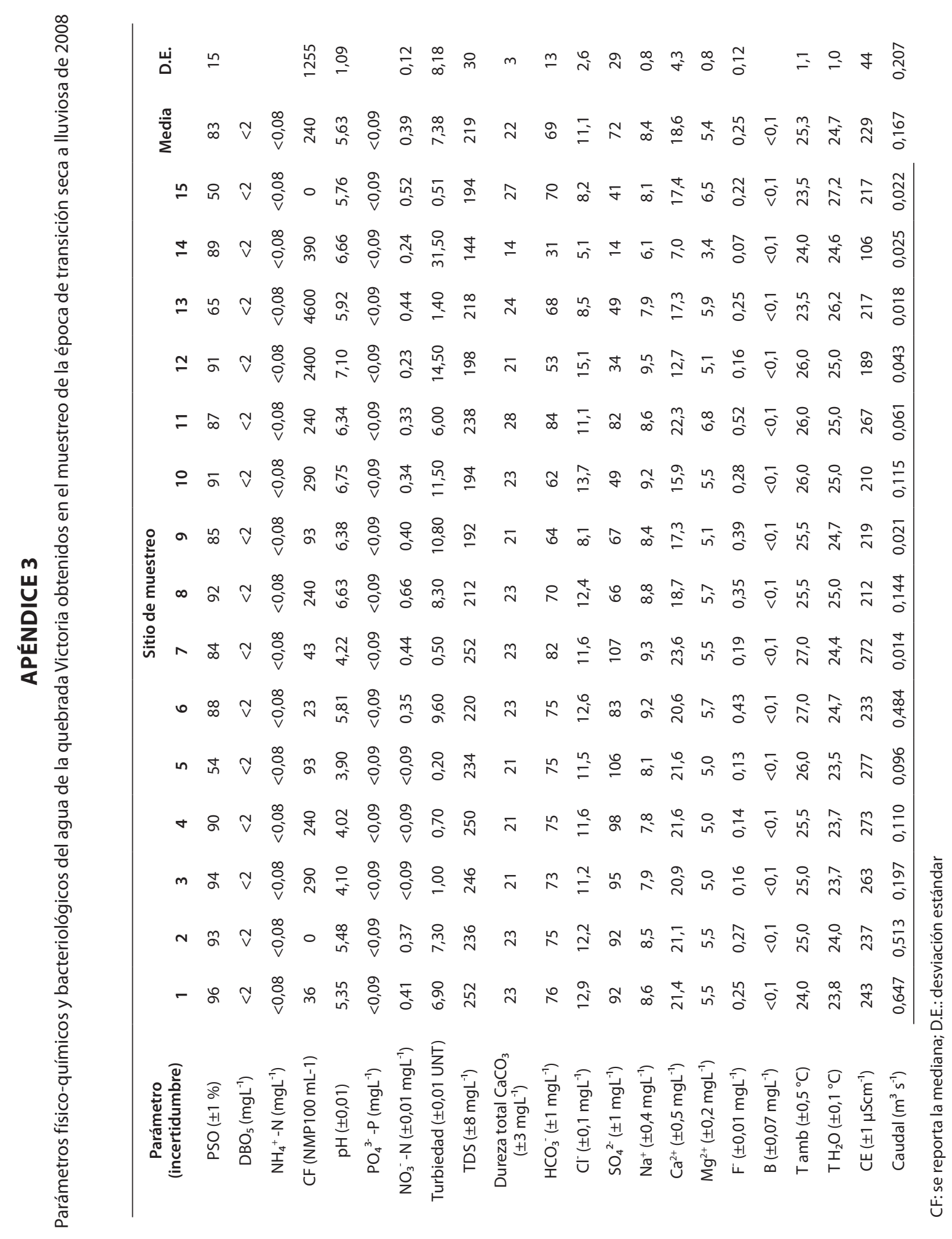


